\title{
Heart rate conditioning as a function of interstimulus interval in rats'
}

ROGER W. BLACK, UNIVERSITY OF SOUTH CAROLINA PATRICIA ELSTAD BLACK, COLUMBIA COLLEGE

Relatively unrestrained rats received $H R$ conditioning consisting of the presentation of a white noise CS followed by electric shock UCS. Four groups received delayed ISIs of $.05,2.5,5.0$ or $10.0 \mathrm{sec}$ respectively and a control group received CS only. All groups showed deceleration on initial trials followed by acceleration on later trials. HR Rs were greatest in the 2.5 and $5.0 \mathrm{sec}$ groups and least for CS-only. Discrepancies regarding the direction of conditioned $H R$ changes are noted.

It is well known that the optimal interstimulus interval (ISI) in classical skeletal conditioning is about .5 sec. Very little conditioning appears to occur with such CRs with simultaneous and backward intervals or with forward intervals in excess of $2.0 \mathrm{sec}$ or so. Similar results have also been reported by some Es for autonomic CRs such as the GSR (e.g., Moeller, 1954). Other Es, however, have reported effectlve autonomic (GSR) conditioning over a much wider range of ISIs and have suggested that this may be due to the longer latency of such Rs (e.g., Champion \& Jones, 1961). Similarly, Church \& Black (1958) found that heart rate (HR) conditioning in restrained dogs was as effective with a $20 \mathrm{sec}$ ISI as with $5 \mathrm{sec}$. These Es did not, however, employ an interval as short as that found most effective with skeletal CRs.

The present study investigated HR conditioning in rats as a function of ISI. The values of ISI selected comprised a range extending from those intervals found most effective in skeletal conditioning to those which are purportedly effective in autonomic, but ineffective in skeletal, conditioning.

Method

The Ss were 85 male albino rats approximately 100 days old. A pair of stainless steel wire electrodes was permanently implanted sub-dermally on each S's back. A pair of wire leads, attached to the electrodes with small alligator clips, delivered cardiac potentials to a Massa Cohu Oscillograph which recorded EKG.

The test chamber consisted of a sound-shielded 12-in. cubicle box. The electrode leads were suspended above the top of the box and were under very slight tension provided by rubber bands. This technique provided $\mathbf{S}$ with relatively complete freedom of movement, while preventing the leads from becoming entangled with the animal. A high frequency speaker mounted at the top of the test chamber was driven by a Gerbrands oscillator and provided a $40 \mathrm{~dB}$ white noise CS. The UCS was a constant current $1.5 \mathrm{~mA}$ electric shock delivered to $S$ through the grid floor of the chamber.

Thirty conditioning followed by 15 extinction trials were administered to each $S$ on a single day. The Ss were placed individually in the test chamber and, following a 20-min adaptation period, conditioning and extinction trials were administered with an average intertrial interval of $2 \mathrm{~min}$ and with delayed ISIs of $.5,2.5,5.0$, and $10.0 \mathrm{sec}$ for the four conditioning groups, respectively. A fifth group ("CS-only") received a 5.5-8ec "CS" on each trial, but was never shocked. During extinction each $S$ received a CS of the duration it had received during conditioning, but no $S$ received shock. There were $20 \mathrm{Ss}$ each in the $.5,2.5$, and $5.0 \mathrm{sec}$ groups; $15 \mathrm{Ss}$ in the $10 \mathrm{sec}$ group and $10 \mathrm{Ss}$ in the CS-only group.

EKG was recorded for $5 \mathrm{sec}$ prior to the onset of the CS and for 20 sec following CS onset. HR was determined for each second of this period and the magnitude of the HR response was defined as the difference in bpm between the $3 \mathrm{sec}$ prior to CS onset and the 3 sec following CS onset for which this difference was greatest.

\section{Results and Discussion}

Figure 1 represents mean HR response in each of the five groups during acquisition and extinction.

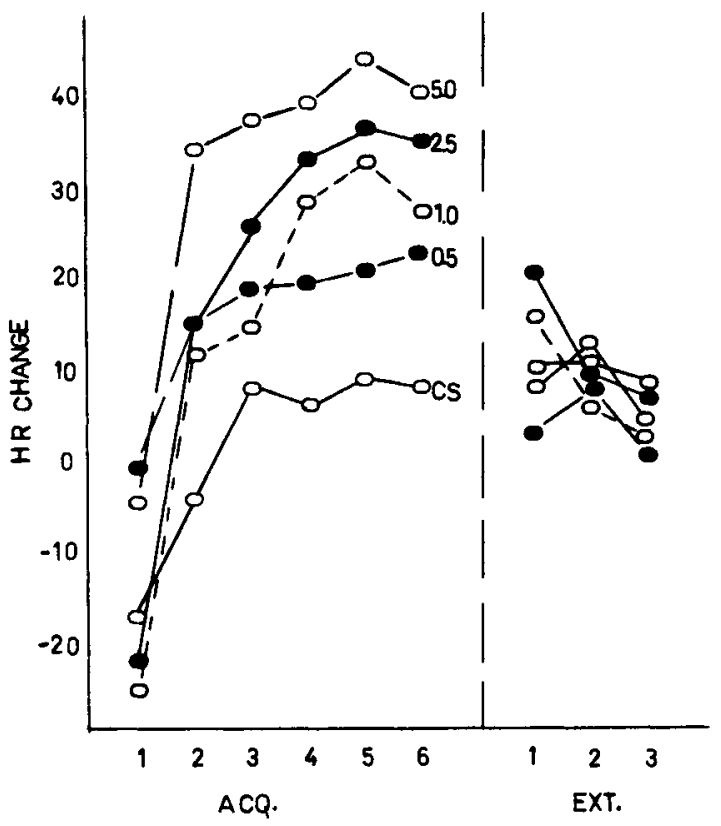

Fig. 1. Mean HR response for each of the five groups on acquisition and extinction test trials. 
Inspection of this figure indicates that a deceleration in HR followed the presentation of the CS in the initial block of trials, while HR acceleration followed the CS on subsequent test trials in each of the groups. Both the initial deceleration and the subsequent change in acceleration in response to auditory stimuli have been previously observed, even in situations where no shock was involved (Black, 1964; Boyles, Black, \& Furchtgott, 1965). It should be noted, however, that in the present case (1) the amount of acceleration on the later trials was greater for the conditioning groups than for CS-only; (2) the amplitude of the HR response in the conditioning groups was related to ISI; (3) the extinction procedure resulted in a decrement in HR response in all conditioning groups to a level not clearly different from that of the CS-only group. Each of these observations was statistically confirmed. Thus, mean HR response was reliably greater on the first two test trials of acquisition for the pooled conditioning groups than for CS-only $(t=2.74, d f=83, p<.001)$. Moreover, within the conditioning groups, mean terminal HR response was significantly greater for Groups 5.0 and $2.5 \mathrm{sec}$ than for Groups .5 and $10.0 \mathrm{sec}(t=2.02, \mathrm{df}=73, \mathrm{p}<.05)$. Finally, the differences both between the conditioning groups and between those groups and the CS-only group disappeared in extinction $(t=1.01, d f=83, p>.30)$.

The present data thus only partially confirm those of Church \& Black (1957). In agreement with those $\mathrm{Es}$, the results suggest that autonomic Rs-at least, HR-can be conditioned at longer ISIs and over a wider range of ISIs than is the case with skeletal CRs. The present data also suggest, however, that HR conditioning is not as effective at $.5 \mathrm{sec}$ or at the 20 sec interval of Church and Black as it is at inter- mediate intervals of 5.0 and $2.5 \mathrm{sec}$. It should be noted, of course, that the present study, unlike that of Church and Black, employed relatively unrestrained Ss. Thus, it may be that HR effects of motor activity were confounded with the conditioning levels presumably reflected in Fig. 1. This possibility has been recently suggested again by Fitzgerald, Vardaris, \& Brown (1966) who reported that the conditioned HR in their rats was consistently a deceleration. These Es note that other investigators have reported accelerative CRs and they suggest that this inconsistency may result from the degree of constraint imposed on $\mathrm{S}$. On the other hand, Black (1965) has effectively argued that "skeletal activity artifacts" do not appear to account for the phenomena of HR conditioning.

\section{References}

Black, A. H. Cardiac conditioning in curarized dogs: The relationship between heart rate and skeletal behavior. In W. F. Prokasy (Ed.), Classical conditioning. New York: Appleton-CenturyCrofts, 1965

Black, R. W. Heart rate response to auditory stimuli of varying duration. Psychon. Sci., 1964, 1, 171-172.

Boyles, W. R., Black, R. W., \& Furchtgott, E. Early experience and cardiac responsibity in the female albino rat. J. comp. physiol. Psychol., 1965, 59, 447-449.

Champion, R. A., \& Jones, J. E. Forward, backward, and pseudoconditioning of the GSR. J. exp. Psychol., 1961, 62, 58-61.

Church, R. M., \& Black, A. H. Latency of the conditioned heart rate as a function of the CSUCS interval. J. comp. physiol. Psychol., 1958, 51, 478,482.

Fitzgerald, R. D., Vardaris, R. M., \& Brown, J. S. Classical conditioning of heart-rate deceleration in the rat with continuous and partial reinforcement. Psychon. Sci., 1966, 6, 437-438.

Moeller, G. O. The CS-UCS interval in GSR conditioning. J. exp. Psychol., 1954, 48, 162-167.

\section{Note}

1. Supported in part by NIH Grant M-6132. 